\title{
Re: A Modified Transurethral Stenting Technique for (Robot-Assisted) Laparoscopic Ureteral Reimplantation
}

\author{
Leslie A. Deane \\ Department of Urology, University of Miami Miller School of Medicine, Miami, FL, USA
}

Dear Editor,

The technique described herein as a "Modified Transurethral Stenting Technique" is a safe and easy method to facilitate stent placement during ureteral reimplantation and is especially tailored for such, when immersed in a laparoscopic or robotic environment for these technically challenging procedures. It provides several similarities to traditional retrograde stent placement, including direct inline guide wire advancement up the ureter and use of a pusher catheter to advance the stent. It effectively eliminates any uncertainty of feeding the guide wire into the ureter at any angle other than $0^{\circ}$, thus minimizing the risk of ureteral trauma and possible submucosal passage and simplifies passage for the bedside assistant.

Indeed, this technique has previously been reported by Yang et al. [1] and has been routinely utilized in numerous procedures of this kind for more than a decade. It has also previously been presented in abstract/video format by Sarvepalli et al. [2], in a compilation of "Minimally Invasive, Robotic Ureteral Surgery: An Illustrated Techniques Video."

To be sure, the technique simplifies the retrograde placement of an ureteral stent during robotic ureteral reimplantation and has reduced the uncertainty that can occur with other techniques for retrograde placement, all the while being a more familiar method for even the least experienced assistants.

\section{Conflict of Interest Statement}

The authors have no conflicts of interest to declare.

\section{Funding Sources}

The authors did not receive any funding.

\begin{tabular}{|c|c|}
\hline References & $\begin{array}{l}1 \text { Yang C, Jones L, Rivera ME, Verlee GT, } \\
\text { Deane LA. Robotic-assisted ureteral reim- } \\
\text { plantation with Boari flap and psoas hitch: a } \\
\text { single-institution experience. J Laparoendosc } \\
\text { Adv Surg Tech A. } 2011 \text { Nov;21(9):829-33. } \\
2 \text { Sarvepalli S, Larsen S, Padilla W, Deane L. } \\
\text { Minimally invasive, robotic ureteral surgery: } \\
\text { an illustrated techniques video. J Urol. } 2014 \\
\text { April;191(4S):V4-03, e551. }\end{array}$ \\
\hline
\end{tabular}

karger@karger.com www.karger.com/uin

(c) 2020 S. Karger AG, Basel

Karger"
Leslie A. Deane

Department of Urology, University of Miami Miller School of Medicine 1120 NW 14th Street, Suite 1551

Miami, FL 33136 (USA)

lxd652@miami.edu 